\title{
Atomic Absorption Analysis of Toxic Heavy Metal Impurities in Various Commercial Aspirin Formulations
}

\author{
Somaya Al-Sadeq Al-Taeb ${ }^{1}$, Khairi Al-Sadeq Ahmed Al-Tayeb ${ }^{2}$, Abdussalam Salem Al-Aseer ${ }^{1}$, \\ Mohammad Mushahid Khan ${ }^{3, *}$
}

${ }^{1}$ Department of Chemistry, Academy of Higher Education, and University of Zawia, AZ-Zawia, Libya

${ }^{2}$ Department of ENT, School of Medicine, University of Pretoria, Pretoria, South Africa

${ }^{3}$ Department of Biochemistry and Molecular Biology, Faculty of Medicine, University of Zawia, AZ-Zawia, Libya

\author{
Email address: \\ mmkhan@zu.edu.ly (M. M. Khan)
}

\section{To cite this article:}

Somaya Al-Sadeq Al-Taeb, Khairi Al-Sadeq Ahmed Al-Tayeb, Abdussalam Salem Al-Aseer, Mohammad Mushahid Khan. Atomic Absorption Analysis of Toxic Heavy Metal Impurities in Various Commercial Aspirin Formulations. Advances in Biochemistry.

Vol. 3, No. 1, 2015, pp. 9-14. doi: 10.11648/j.ab.20150301.13

\begin{abstract}
Aspirin is the most extensively used mild analgesic and antipyretic drug. In Libya as well as worldwide, aspirin is purchased without prescription in many forms and is imported into the country without any control. However, conditions for packing, storing and preventing the drug from damage are not properly followed. There are no supervision or quality control procedures on the validity and chemical composition of the drug. In this study, thirteen available aspirin forms imported from different countries and one sample from local factory were collected and analyzed for comparison. The quality of the samples was examined in terms of active ingredient (acetyl salicylic acid- ASA), toxic heavy metal and salicylic acid impurities. ASA contents were analyzed using volumetric titration and HPLC method. The toxic heavy metal impurities were determined using atomic absorption spectrophotometry, and salicylic acid impurity was determined by fluorimetric method. The active ASA contents were found in the range from 87 to $104 \%$. Comparison of the determined ASA contents with the actual contents per tablet indicated that only $14 \%$ of the samples were in identical values, whereas; $57.1 \%$ were exceeded and $28.6 \%$ were less than the actual content per tablet. The salicylic acid impurities were under permissible limit. Although, the results for the toxic heavy metals impurities showed significant variations among the samples, but all were under the limit permitted by the world health organization.
\end{abstract}

Keywords: Aspirin, Salicylic Acid, Acetylsalicylic Acid, Toxic Heavy Metal, Atomic Absorption Spectroscopy, HPLC

\section{Introduction}

Aspirin (acetylsalicylic acid) is one of the most widely used minor analgesics. It is used to relieve minor aches and pains, as an antipyretic to reduce fever, and as an antiinflammatory medication (Cheng, 2007, Aukerman et al. 2000, Jeffreys 2005, Reynolds 1982, Krumholz et al, 1995, Tang et al, 2012). Long-term therapy with low dose of aspirin has also been used to prevent heart attacks, strokes, and blood clot formation in people at high risk (Brambilla et al, 2010, Smith et al, 2012). It has also been suggested that low doses of aspirin may be given immediately after acute myocardial infarction to reduce the risk of re-infarction (Krumholz et al, 1995, Borzak et al, 1998, Marcus \& Broekman 1998, American Heart Association 2008). There are also some side effects associated with the regular use of aspirin such as lung cancer, colon cancer, gastrointestinal bleeding etc. (Moysich et al., 2002. Temple 1981, Endo et al. 2014)

The purity and homogeneity of aspirin preparations has been debated over several years. The main concerns regarding the aspirin preparations have been active ingredients and the impurities of salicylic acid and toxic heavy metals. One study, analyzing active ASA ingredients in several aspirin brands, found that $\sim 5 \%$ tested samples were failed to meet the USPXIX limits for active ASA contents and $\sim 10 \%$ failed to meet the limits for salicylic acid impurity (Juhl \& Kirchhoefer, 1980). Another study found that some of the aspirin formulations contained salicylic acid impurity exceeding the USP 1980 limit of $0.3 \%$ salicylic acid per tablet (Salako et al., 1989). 
Frenata et al. (2002) and Rodrigues et al, (2004) have determined active acetylsalicylic acid (ASA) contents in various aspirin samples, and the results obtained were comparable to the results obtained by pharmacopeia titration method and HPLC method. Yang et al. (2004) have also analyzed active ASA ingredients in various aspirin brands and found that some aspirin brands may contain up to $110 \%$ of active ASA contents. Miyoshi \& Saiki (2009) and Iskandar et al. (1986) have analyzed various trace elements by using 'instrumental neutron activity analysis (INAA)' of trace element in various aspirin samples. The results obtained by these investigators were comparable with the certified standard reference materials for various trace elements as reported in The International Pharmacopeia (WHO, 2011). In another study, using a quantitative HPLC method determined salicylic acid impurities in bulk aspirin and plane buffered aspirin tablets (Kirchhoefer \& Juhl, 1980). They found that excipients and impurities did not interfere with the quantification and the recovery was $100 \%$ and salicylic acid impurities were within the limit. The above studies, though, have made systematic analysis of various impurities in different aspirin brands but in most of these studies, the samples size was low. Therefore, we have made a systematic quantitative analysis of a large number of aspirin samples in terms of active ingredients, toxic heavy metals and salicylic acid impurities.

\section{Materials and Methods}

\subsection{Materials}

Salicylic acid (99.8\%) was purchased from Riedel-DeHaen, Germany. Acetyl salicylic acid (ASA), analytical grade was obtained from GRR, India. All other reagents used were of analytical grade reagents unless otherwise stated. Heavy metal standards including: arsenic, cadmium, chromium, lead, were purchased as readymade stock solutions from BDH Spectrosol, UK. Aspirin samples (in the form of tablets were collected randomly from various pharmacies around Tripoli and Zawia regions. The period of samples collection was scheduled from November 2008 to January 2009. Samples were collected in duplicates containing $300 \mathrm{mg}$ and $100 \mathrm{mg}$ active aspirin contents.

\subsection{Methods}

\subsubsection{High Performance Liquid Chromatography (HPLC)}

The acetylsalicylic acid (ASA) contents were analyzed on a Shimadzu Model LC-10AS liquid chromatography equipped with SPD-M10A diode array detector and SIL -10A auto injector. An appropriate amount aspirin sample was extracted with a mobile phase solution (Acetonitrile. Methanol and $20 \mathrm{mM}$ sodium phosphate buffer of $\mathrm{pH}=3$, in a portion 50:7:43 v/v). The extracts were made up to the volume $(50 \mathrm{ml})$ with mobile phase and further dilutions were carried out to get a concentration of $30 \mu \mathrm{g} / \mathrm{ml}$ of acetyl salicylic acid. The contents were mixed thoroughly and filtered through $0.45 \mu \mathrm{m}$ filter paper. An aliquot of $20 \mu \mathrm{l}$ of both standard and test solutions were injected separately under the described conditions (Figure 1A and B). A stock solution containing $150 \mu \mathrm{g} / \mathrm{ml}(150 \mathrm{ppm})$ of acetylsalicylic acid was prepared by transferring $15 \mathrm{mg}$ of the pure acetylsalicylic acid into $100 \mathrm{ml}$ volumetric flask and dissolved in a solution of $50 \%$ acetonitrile in water. From this stock solution a series of calibration solutions were prepared containing 20,40, 60 and $80 \mu \mathrm{g} / \mathrm{ml}$ acetylsalicylic acid in the same solvent and the calibration curve was drawn to calculate the concentration of ASA in various aspirin samples (Kirchhoefer \& Juhl, 1980, Cham, 1980).

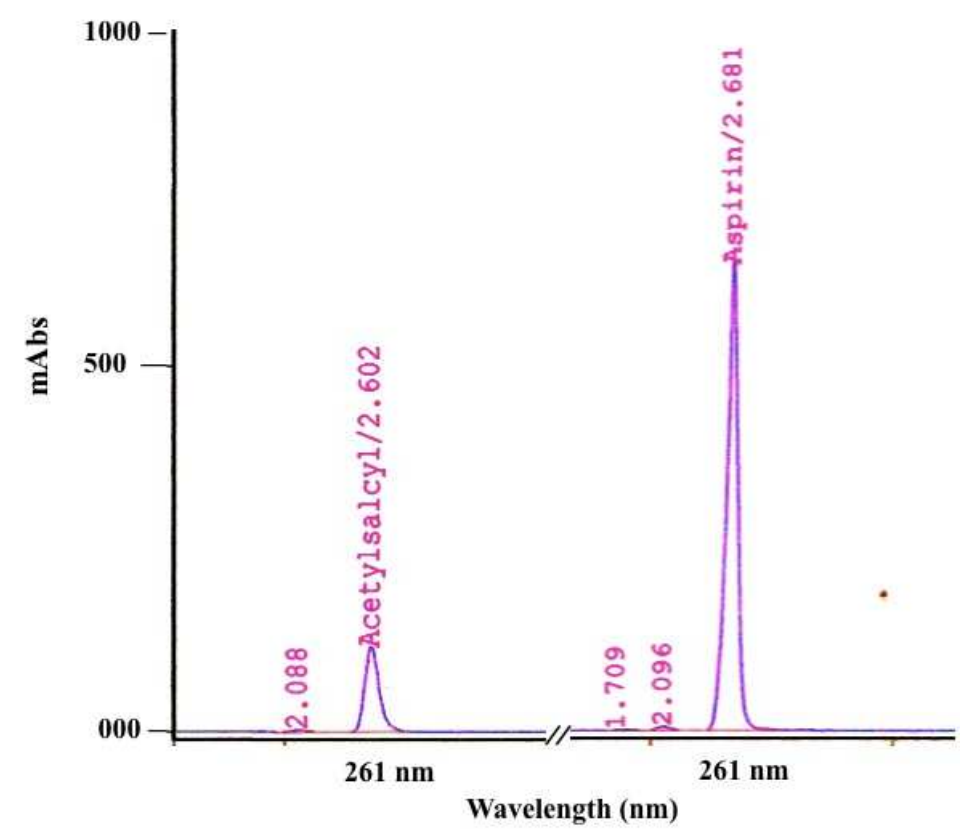

Figure 1. The HPLC response of a standard solution of; A) acetylsalicylic acid. B) HPLC response of an aspirin sample under similar experimental conditions. 


\subsubsection{Volumetric Titration}

The active ASA ingredients in various aspirin samples were also determined using volumetric titration method. A quantity of the powder sample containing $0.5 \mathrm{~g}$ of aspirin was weighed in a glass beaker and $30 \mathrm{ml}$ of $0.5 \mathrm{~N} \mathrm{NaOH}$ was added and the mixture was boiled gently for 10 minutes. The excess of unreacted $\mathrm{NaOH}$ was titrated with $0.5 \mathrm{~N} \mathrm{HCl}$ using phenol red solution as indicator. A blank solution containing all the reagents except aspirin was also titrated. The difference between the titrations represents the amount of $\mathrm{NaOH}$ consumed by the aspirin (acetylsalcylic acid). Therefore, each $\mathrm{ml}$ of $\mathrm{NaOH}$ consumed is equivalent to 0.04504 gram of $\mathrm{C}_{9} \mathrm{H}_{8} \mathrm{O}_{4}$. The procedure was repeated three times for each sample and the results were analyzed by taking the average.

\subsubsection{Atomic Absorption Spectroscopy}

Toxic heavy metal impurities were analyzed using atomic absorption spectroscopy performed on a Shimadzu type AA6701F atomic spectrophotometer attached to a graphite furnace and out-injector (ASC6000). This method has been used to determine heavy metal contents in various chemical preparations. All the experiments were run in triplicate and the data were collected using automatic processor attached to a PC

Working solutions of trace elements were prepared daily by appropriate dilution $(0,1,5,10,15$ and $20 \mathrm{ml})$ of standard heavy metal stock solution $(10 \mathrm{ppm})$. The solutions were transferred to each of six $100 \mathrm{ml}$ volumetric flasks and $5 \mathrm{ml}$ of concentrated $\mathrm{HNO}_{3}$ was added to each flask. The volumes were completed with deionized water to $100 \mathrm{ml}$ giving $0,0.1$, $0.5,1.0,1.5$ and $2 \mathrm{ppm}$ concentration of each heavy metal. A calibration curve was drawn by running serial dilutions of the standard heavy metals as described by manufacturer. The corresponding absorption values were recorded and fitted by using linear regression method (Figure 1). The concentration of trace elements in various aspirin samples was calculated from the calibration curve using the 'slope' and 'intercept' values obtained by linear regression method. Aspirin samples were prepared by dissolving an appropriate powder of aspirin tablets in $10 \mathrm{ml}$ of concentrated nitric acid. The mixture was then carefully heated on hot plate to dryness. Then $5 \mathrm{ml}$ of hydrogen peroxide was added and heated again to dryness. The residue was then treated with $20 \mathrm{ml}$ of $0.1 \mathrm{~N} \mathrm{HNO}_{3}$ and stirred for 10 minutes. The sample solution was then filtered into $50 \mathrm{ml}$ volumetric flask and the volume was made with double distilled water.

\subsubsection{Fluorometry}

The fluorimetric analysis for salicylic acid in aspirin samples was carried on a Shimadzu Model Rf-5301 PC spectrofluorometer. The instrumental conditions used were set as follows: Excitation wavelength $\lambda_{\mathrm{Ex}}=298.0 \mathrm{~nm}$ and Emission wavelength $\lambda_{\mathrm{Em}}=410.0 \mathrm{~nm}$. The calibration curve was constructed using the pre described standards using $(1 \mathrm{~cm})$ quartiz cell. The aspirin samples were then measured for the salicylic acid impurities as follow. A $20 \mathrm{mg}$ sample of the fine aspirin powder was transferred into $250 \mathrm{ml}$ volumetric flask. $40 \mathrm{ml}$ of sodium fluoride-hydrochloric acid solution was added and the mixture shaken for five minutes. After 10 minutes with frequent shaking the solution mixture was diluted to the volume using buffer solution $\mathrm{pH}=4$. The solution was then filtered through whatman filter paper (No: 541 ) and $2 \mathrm{ml}$ of the filtrate was diluted to $100 \mathrm{ml}$ with the buffer and this solution was measured fluorometrically at 410 nm (White \& Weissler, 1972).

A stock solution containing $10 \mu \mathrm{g} / \mathrm{ml}(150 \mathrm{ppm})$ of salicylic acid was prepared by transferring $10 \mathrm{mg}$ of the pure salicylic acid into a $250 \mathrm{ml}$ volumetric flask and dissolved in $40 \mathrm{ml}$ of sodium fluoride-hydrochloric acid solution after frequent shaking for 15 minutes the volume was completed to the mark using buffer $\mathrm{pH}=4$. From this stock solution a series of calibration solutions were prepared containing 0,2 , 5,20 and $60 \mu \mathrm{g} / \mathrm{ml}$ salicylic acid in the same solvent.

\section{Results and Discussion}

\subsection{Acetylsalicylic Acid Contents}

The acetylsalicylic acid contents (ASA) were determined using HPLC and volumetric titration. First, linearity and purity of the standard ASA solutions was established on HPLC column. Fig. 1A shows the HPLC elution profile of a standard solution of ASA. As can be seen from the Fig. 1A that the response of standard ASA on HPLC column was linear and gave a single peak within the expected range. Then triplicate injections of several standard solutions of ASA were loaded on to the HPLC column and the mean peak areas were taken into account to draw the calibration curve. Various aspirin samples were then eluted through the same HPLC column and each sample gave a single peak within the expected range as show in Fig. 1B. The peak area of all the aspirin samples was then measured, and using the calibration curved drawn from the above standards, contents of ASA in various aspirin samples were calculated and the results are shown in the table 1 (middle column). The results of ASA contents as obtained by HPLC were further confirmed by using volumetric titration method and the data is shown in table 1 (right column). As can be seen from the table 1 , that the ASA contents in various aspirin samples obtained by titration method were more or less similar to that obtained by HPLC methods. Further, as can be seen from the table 1 that the range ASA contents in various aspirin samples varies from 87.70 - 104\%. Except, two samples (AS6, AS7), which contained $<90 \%$ ASA contents, remaining aspirin samples were in good agreement and and contained $>90 \%$ active ASA ingredients. Further, shown in table 2 are the comparison of the ASA contents formulated by the respective pharmaceutical company and the actual ASA contents determined in the laboratory. As can be seen from the table 2 that ASA contents of most of the samples formulated by the companies showed deviation from those determined in the laboratory, but were within the permissible limits. These results are in agreement with various reports on the active ASA 
contents in commercial aspirin preparation (Franeta et al, 2002, Salako et al., 1989, Juhl \& Kirchhoefer, 1980, Cham, 1980).

Table 1. Table shows the comparison of the acetylsalicylic acid content in various aspirin samples determined by both volumetric titration method and HPLC.

\begin{tabular}{lll}
\hline & \multicolumn{2}{l}{ Acetylsalicylic acid (\%) } \\
\cline { 2 - 3 } Sample no. & $\begin{array}{l}\text { Determined by HPLC } \\
\text { method }\end{array}$ & $\begin{array}{l}\text { Determined by titration } \\
\text { method }\end{array}$ \\
\hline AS1 & $98.4 \pm 1.33$ & $97.49 \pm 0.76$ \\
AS2 & $87.9 \pm 3.21$ & $100 \pm 1.07$ \\
AS3 & $97.0 \pm 1.21$ & $97.0 \pm 1.91$ \\
AS4 & $99.8 \pm 1.0$ & $100 \pm 1.6$ \\
AS5 & $99.4 \pm 0.87$ & $99.8 \pm 0.87$ \\
AS6 & $87.8 \pm 3.41$ & $93.6 \pm 4.81$ \\
AS7 & $87.7 \pm 2.22$ & $104 \pm 2.09$ \\
AS8 & $97.4 \pm 0.81$ & $105 \pm 3.32$ \\
AS9 & $92.0 \pm 4.62$ & $92.0 \pm 3.42$ \\
AS10 & $96.2 \pm 2.06$ & $96 \pm 3.08$ \\
AS11 & $93.2 \pm 4.55$ & $93.2 \pm 4.02$ \\
AS12 & $101 \pm 0.78$ & $101 \pm 2.08$ \\
AS13 & $99.0 \pm 1.66$ & $99.0 \pm 1.23$ \\
AS14 & $95.0 \pm 0.21$ & $95.0 \pm 0.01$ \\
\hline
\end{tabular}

Table 2. Comparison of acetylsalicylic acid (ASA) contents formulated by the pharmaceutical companies with the actual ASA contents determined in the laboratory.

\begin{tabular}{lll}
\hline Sample no. & $\begin{array}{l}\text { Formulated in the } \\
\text { company }\end{array}$ & $\begin{array}{l}\text { Determined in the } \\
\text { laboratory }\end{array}$ \\
\hline AS1 & $300 \mathrm{mg}$ & $292.5 \mathrm{mg}$ \\
AS2 & $300 \mathrm{mg}$ & $303.0 \mathrm{mg}$ \\
AS3 & $300 \mathrm{mg}$ & $291.0 \mathrm{mg}$ \\
AS4 & $300 \mathrm{mg}$ & $300.0 \mathrm{mg}$ \\
AS5 & $300 \mathrm{mg}$ & $299.4 \mathrm{mg}$ \\
AS6 & $300 \mathrm{mg}$ & $288.9 \mathrm{mg}$ \\
AS7 & $300 \mathrm{mg}$ & $312.0 \mathrm{mg}$ \\
AS8 & $320 \mathrm{mg}$ & $336.0 \mathrm{mg}$ \\
AS9 & $300 \mathrm{mg}$ & $276.0 \mathrm{mg}$ \\
AS10 & $100 \mathrm{mg}$ & $96.3 \mathrm{mg}$ \\
AS11 & $75 \mathrm{mg}$ & $69.9 \mathrm{mg}$ \\
AS12 & $100 \mathrm{mg}$ & $101.0 \mathrm{mg}$ \\
AS13 & $81 \mathrm{mg}$ & $80.20 \mathrm{mg}$ \\
AS14 & $81 \mathrm{mg}$ & $76.9 \mathrm{mg}$ \\
\hline
\end{tabular}

\subsection{Toxic Heavy Metal Impurities}

We next examined the toxic heavy metal impurities in various aspirin samples. The four heavy metal of serious health concern, which includes: lead, chromium, cadmium, and arsenic were analyzed using graphite furnace atomic absorption spectroscopy. The analysis of the samples was made in triplicate and the average value was used in calculation. Fig. 2, shows the calibration curve of standard heavy metaled drawn by using atomic absorption spectroscopy. Using this calibration curve, concentration of four toxic heavy metals namely; lead, cadmium arsenic, and chromium in various aspirin brands were determined and the results are shown in the table 3 . The results indicate that all the determined heavy metals were within the permissible limit directed by the world health organization (WHO; The International Pharmacopeia, 2011). However, variation between the concentrations of the heavy metals in all the samples was obvious. The level of lead was the highest among the rest and ranged from 0.002 to $0.054 \mathrm{ppm}$. Chromium ranked the second in its concentration levels and ranged from $<0.001$ to $0.028 \mathrm{ppm}$. As can also be seen from the table 3 that two samples (AS9 and AS12) contain the highest concentrations of lead and chromium (table 3 ). Comparing our obtained results with those previously obtained by the work of Miyoshi et al., (2009), they found the concentration of chromium ranged from $<24$ to $658 \mu \mathrm{g} / \mathrm{kg}$ in aspirin samples, where as in our results chromium concentration ranged from $<1.0$ to $28 \mu \mathrm{g} / \mathrm{kg}$. Nevertheless, in both cases the concentration of chromium and other heavy metals was with the permissible limits.

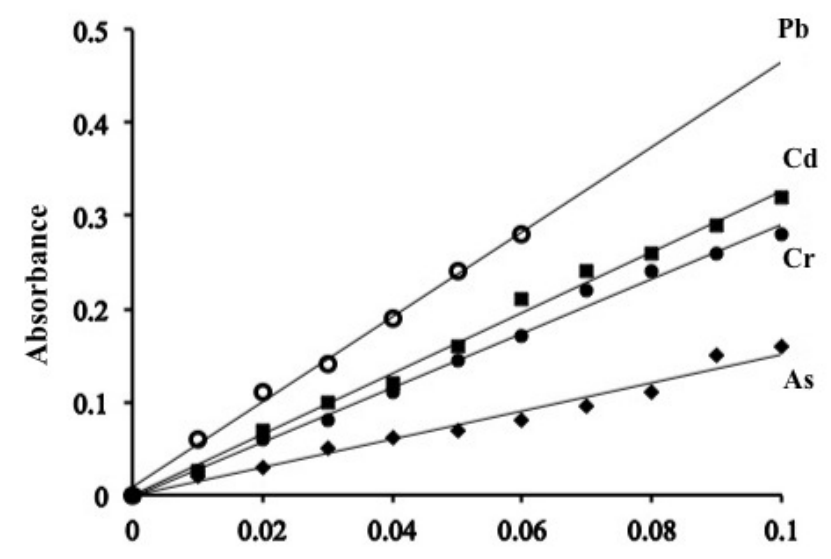

Concentration in (M)

Figure 2. Calibration curves for the standard heavy metals; lead (Pb), cadmium (Cd), chromium (Cr) and arsenic (As). The value of 'slope' and 'intercept' were calculated by linear regression method and used to determine the concentration of heavy metals in various aspirin brands.

Table 3. Table shows the concentrations of toxic heavy metals impurities in various commercial aspirin preparation determined by atomic absorption spectroscopy.

\begin{tabular}{lllll}
\hline \multirow{2}{*}{ Sample no. } & \multicolumn{4}{l}{ Heavy metal concentration $(\boldsymbol{\mu g} / \mathbf{g})$} \\
\cline { 2 - 5 } & Pb & Cr & Cd & As \\
\hline AS1 & 0.010 & 0.011 & 0.001 & 0.001 \\
AS2 & 0.003 & $<0.001$ & 0.005 & $<0.001$ \\
AS3 & 0.017 & $<0.001$ & 0.010 & 0.003 \\
AS4 & 0.003 & $<0.001$ & $<0.001$ & $<0.001$ \\
AS5 & 0.003 & $<0.001$ & $<0.001$ & $<0.001$ \\
AS6 & 0.006 & $<0.001$ & 0.012 & $<0.001$ \\
AS7 & 0.002 & $<0.002$ & 0.016 & $<0.001$ \\
AS8 & 0.017 & 0.009 & $<0.001$ & 0.001 \\
AS9 & 0.054 & 0.015 & $<0.001$ & 0.003 \\
AS10 & 0.016 & 0.016 & $<0.001$ & 0.001 \\
AS11 & 0.015 & 0.017 & $<0.001$ & 0.005 \\
AS12 & 0.008 & 0.028 & $<0.001$ & $<0.001$ \\
AS13 & 0.013 & 0.019 & $<0.001$ & 0.002 \\
AS14 & 0.002 & 0.018 & $<0.001$ & $<0.001$ \\
\hline
\end{tabular}

\subsection{Salicylic Acid Impurities}

The second possible impurity determined in various aspirin tablets is the salicylic acid percentage. Table 4, shows the fluorometric analysis of salicylic acid percentage in the aspirin samples, which ranged from $0.0906 \%$ to $0.138 \%$. The results indicate that the salicylic acid impurities were within the permitted levels. The upper limit is $0.3 \%$ as suggested by 
Bamigbola et al. (2009). Juhl and Kirchhoefer (1980) found that $10 \%$ of the studied samples failed to meet the permitted limit of salicylic acid impurities in their study. Salako, et al. (1989) also found that some of the samples samples exceeded the limit as they analyzed twelve aspirin samples.

In conclusion, the results presented in this study suggest that active ASA ingredients vary for most of the collected aspirin samples, however; they were not of great significance. Nevertheless, they trigger the need for quality control assurance for all types of medicine. Furthermore, active ASA ingredients as determined by HPLC and volumetric titration method showed significant variations among samples but in all the cases ASA contents in aspirin samples were within the permissible limits. Trace element impurities in various aspirin samples were also found within the permissible limits as set by world health organization (WHO, 2011), however; variations exist among various aspirin samples. Similarly, salicylic acid impurities observed in most of the aspirin samples were also found within the permitted limits, however; variation exists among various aspirin samples.

Table 4. Table presents the percentage of the salicylic acid impurities in the aspirin samples determined by fluorometric spectroscopy.

\begin{tabular}{ll}
\hline Sample no. & Salicylic acid (\%) \\
\hline AS1 & 0.0906 \\
AS2 & 0.0920 \\
AS3 & 0.1116 \\
AS4 & 0.1073 \\
AS5 & 0.1381 \\
AS6 & 0.1049 \\
AS7 & 0.0965 \\
AS8 & 0.1033 \\
AS9 & 0.1228 \\
AS10 & 0.1289 \\
AS11 & 0.0951 \\
AS12 & 0.1061 \\
AS13 & 0.1123 \\
AS14 & 0.1160 \\
\hline
\end{tabular}

\section{Acknowledgement}

The facilities provided by the Department of Chemistry, Academy of Higher education, and the National Medical Research Center, Zawia, Libya are gratefully acknowledged

\section{References}

[1] American Heart Association (2008). Aspirin in Heart Attack and Stroke Prevention. http://www.americanheart.org/presenter.jhtmlidentifier4456

[2] Aukerman, G., Knutson, D., Miser, W.F., 2000. Management of the acute migraine headache. American Family and Physician, 66 (11), 2123-30.

[3] Borzak, S., Cannon, C.P., Kraft, P.L., Douthat, L., Becker, R.C., Palmeri, S.T., Henry, T., Hochman, J.S., Fuchs, J., Antman, E.M., McCabe, C., Braunwald, E., 1998. Effects of Prior Aspirin and Anti-Ischemic Therapy on Outcome of Patients with Unstable Angina. American Journal Cardiology, 81(6), 678-681.
[4] Brambilla, M., Parolari, A., Camera, M., Colli, S., Eligini, S., Centenaro, C., Anselmo, A., Alamanni, F., Tremoli, E., 2010. Effect of two doses of aspirin on thromboxane biosynthesis and platelet function in patients undergoing coronary surgery. Thrombosis Haemostasis, 2010, 103(3), 516-24.

[5] Cham, E. B., Lesley, R.L., Felix, B., Imhoff, D. M., 1980. Measurement and Pharmacokinetics of Acetylsalicylic Acid by a Novel High Performance Liquid Chromatographic Assay. Therapeutic drug monitoring, 2, 365-372.

[6] Cheng, T.O., 2007. The History of Aspirin. Texas Heart Institute Journal, 34(3), 392-393.

[7] Endo, H, Sakai, E, Kato, T, Umezawa, S, Higurashi, T, Ohkubo, H, Nakajima, A., 2014. Small bowel injury in lowdose aspirin users. Journal Gastroenterology, Dec 14. [Epub ahead of print]

[8] Franeta, J.T., Agbaba, D., Eric, S., Pavkov, S. Aleksic, M., and Vladimiro, S., 2002. HPLC assay of acetylsalicylic acid, paracetamol, caffeine, and Phenobarbital in tablets. II Farmaco, 57(9), 709-713.

[9] Iskander, F.Y., Klein, D. E., Bauer, T. L., 1986. Determination of trace element impurities in aspirin tablets by neutron activation analysis, Journal of Radio Analytical and Nuclear Chemistry, 97 (2), 353-357

[10] Jeffreys, D., 2005. Aspirin: The Remarkable Story of a Wonder Drug. Bloomsbury USA. pp.73-269.

[11] Juhl, W. E., and Kirchhoefer, R. D., 1980. Aspirin - a national survey I: Semiautomated determination of aspirin in bulk and tablet formulations and salicylic acid in tablet formulations. Journal Pharmaceutical Sciences, 69(5), 544-548.

[12] Kirchhoefer, R. D., and Juhl, W. E. 1980. Aspirin- a national survey II: determination of salicylic acid in bulk aspirin and aspirin formulation by high-pressure liquid chromatography using a fluorescence detector. Journal Pharmaceutical Sciences, 69(5), 544-548.

[13] Krumholz, H. M., Radford, M. J., Ellerbeck, E.F., Hennen, J., Meehan, T.P., Petrillo, M., Wang, Y., Kresowik, T.F., Jencks, S. F., 1995. Aspirin in the Treatment of Acute Myocardial Infarction in Elderly Medicare Beneficiaries: Patterns of Use and Outcomes. Circulation, 92 (10), 2841-2847

[14] Marcus, A.J., Broekman, M.J., 1998. Aspirin analogs as antithrombotic agents. Journal of Laboratory and Clinical Medicine, 132 (6), 446-447

[15] Miyoshi, E., Saiki, K., 2009. Trace element impurity determination in aspirin tablets by INAA Journal of Radio Analytical and Nuclear Chemistry, 280 (2) 299-301.

[16] Moysich, K.B., Menezes, R.J., Ronsani, A., 2002) Regular aspirin use and lung cancer risk. BMC Cancer, 2, pp. 31.

[17] Reynolds, E. F., (ed) (1982). Aspirin and similar analgesic and anti-inflammatory agents. Martindale, The Extra Pharmacopoeia 28 Ed, pp.234-82.

[18] Rodrigues, A. Jr., Vila Marta, M.D.C., and Tubino, M., 2004. Acetylsalicylic Acid Determination in Remedies Using a GasDiffusion Flow Injection Analysis (2). Journal of Flow Injection Analysis, 21(1), 25-27.

[19] Salako, Q., Fadiran, E.O., Thomas, W.O., 1989. Detection and determination of salicylic acid impurity in aspirin tablet formulation by HPLC. African Journal of Medicine and Medical Sciences 18(3), 215-218. 
[20] Smith, J.P., Haddad, E.V., Taylor, M.B., Oram, D., Blakemore, D., Chen, Q., Boutaud, O., Oates, J.A. 2012. Suboptimal inhibition of platelet cyclooxygenase-1 by aspirin in metabolic syndrome. Hypertension, 59(3), 719-25.

[21] Tang, S.Y., Sivakumar, M., Ng, A.M., Shridharan, P. 2012. Anti-inflammatory and analgesic activity of novel oral aspirinloaded nanoemulsion and nano multiple emulsion formulations generated using ultrasound cavitation. International Journal Pharmmaceutics, 430(1-2), 299-306.
[22] Temple, A. R., 1981. Acute and chronic effects of aspirin toxicity and their treatment. Archive of Internal Medicine, 141 (3), 364-9.

[23] White, C. E., Weissler, A., (1972). Fluorometric analysis, Analytical Chemistry, 44, 182-206.

[24] WHO. The international Pharmacopeia (2011)

[25] Yang, D., Pinyupa, P., Nuwat, V., and Soravoot, R., 2004. Quality of pharmaceutical items available from drug stores in Phnom Penh, Cambodia 35(3), 741-747. 